\title{
Essay:
}

\section{Life as Moving Towards the Other}

by

Anders Lindseth

Professor emeritus

University of Nordland

Email: anders.lindseth@uin.no 
The ethics of Knud Ejler Løgstrup (1905-1981) is relation ethics. It raises the question of how we can do justice to the life of the Other as it is laid in our hands. In this paper, I start out with an ethical dilemma, clarify the concepts of decision ethics and relation ethics, and I then present the ethics of Løgstrup understood as relation ethics. Lastly, I discuss the important question - within the fields of social work, health care, psychotherapy and pedagogical practices - of how we can meet people in need of our help in an ethical way.

\section{An ethical dilemma}

In 1991, I held a two-day ethics seminar at a psychiatric hospital in Troms $\varnothing$. On the second and last day of the seminar, the chief psychiatrist of the hospital introduced the following ethical dilemma: A 70-year-old female patient at the long-term department refused to wash herself. Her refusal to engage in personal hygiene led to a conflict within the department. The staff was split into two factions: I will call them the "washing by force faction" and the "persuasion faction". Both factions came up with arguments to support their position. The washing by force faction claimed that it is disgraceful to live under such unhygienic circumstances, and that it would be best for the lady to wash herself. After this quasi-ethical argument, the force faction came up with two further arguments, one therapeutic and one environmental, and the general consensus was that the lady must be seen as being psychotic. She was unable to draw reasonable borders in her behaviour, and therefore she needed help in drawing such borders, particularly in the crucial field of hygiene - even if the means to this help might involve the use of force. Lastly, they argued that the bad smell that came from the lady's room had a negative influence on the department's social environment. The persuasion faction also came up with an ethical-, a therapeuticand an environmental argument. First, it was a neglect of the principle of autonomy to wash her forcefully, as well as being a violation of a basic human right to physically force someone to wash themselves. Second, the lady's resistance indicated that she had certain resources, and that it would be untherapeutic to destroy these resources. Third, it should not be overlooked that the lady's behaviour could be understood as a reasonable reaction to the staff's conflicts. By forcefully washing her, the lady would function as a scapegoat for problems that the staff needed to solve internally. 
The situation described thus far represents an ethical dilemma. The staff seemed to be forced to choose between two options that were both unacceptable (or at least problematic): Either you force the lady to wash herself (or rather: you wash her), or you let it be. The situation seems to present a problem without a good possible solution. Furthermore, the arguments for both sides are rather complex and reveal an entangled and opaque situation. How on earth could a poor academic involved in moral philosophy help to clarify and solve this problem? You would not be surprised if I admitted that I felt quite a strong discomfort when I was confronted with this problem.

After reflecting for a while, I first pointed out that such a problem could only arise within an institution, for it has the following form: What does one do in a psychiatric institution if a patient refuses to wash him/herself? By studying this case, we do not get to know a human being or get to learn anything about existing relationships. The dilemma is taken away from life, so to speak, and is made a general problem of treatment. For example, if the lady were living at home with her daughter, the problem would not arise in such a way because the daughter would somehow solve or not solve the problem of her mother's hygiene. Maybe she would say: "Look, mother, today your niece Hilde and her husband are going to visit you. Time to get washed. l'll give you a hand." And then she would bring her mother to the bathroom maybe under some protest, and maybe with some force - and see that she did not leave until she was washed. This solution to the hygiene problem would not necessarily be better than the "solution" of the psychiatric institution. It could become quite a catastrophe, but it would still differ from the institutional solution, as the lady would at least know whom to be angry with. When an institution decides that the lady shall be washed, this act of coercion is particularly scary due to its impersonal character.

After demonstrating this impersonal character of the problem, I pointed out that a general solution should not be expected. The dilemma had been introduced as if it could have a general solution: "If a psychiatric patient refuses to wash himself, one (i.e. the staff) should act as follows: ...". But pondering this for a while, it is quite surprising that a general solution could be expected at all, because the many cases 
of psychiatric patients refusing to wash themselves are all different. The patients differ, the reason for their behaviour differs, and the skills of the staff and the relationships within the department differ. How on earth could there be the same solution everywhere? I think the reason for this can be found in the staff's wish to master a complex and difficult reality by means of clear principles and guidelines. Once gotten into this dilemma, one wants to give reasons for a solution and justify an option that is helpful for oneself. As understandable as this wish might be, it is clear that this reduction of complexity can be an unjustifiable simplification. The general justification of an action then becomes a self-justification of the staff at the expense of the patient, and a moral of wanting the best for the patient (if it had existed at all) has turned into a moralism that puts principles above human beings. In such a moralism, the Danish philosopher and theologian Knud E. Løgstrup (1972: 42) sees that which emphasizes "moral for the sake of being moral" and the "specific way of the moral to be immoral".

\section{Decision ethics or relation ethics}

I did not realize it at once in this situation at the psychiatric hospital in Troms $\emptyset$, but the dilemma described above led to the insight that a common ethical way of thinking - which I myself had also taught in seminars - can easily turn into something unethical. I would like to describe this way of thinking as follows: A case is reported that represents an ethical problem, quite often an ethical dilemma. The description of this situation aims at clarifying facts and arguments in such a way that distinct alternatives can be demonstrated, and ethical models or theories are then referred to. By applying ethical principles, or by looking at the possible effects of the alternatives, these models or theories shall lead to a decision about which option is the best and should therefore be chosen. I think the ethical dilemma described above indicates a certain danger in this way of ethical thinking: The danger that the problematic situation is not clarified enough! The situation often has a pressure for deciding that can easily lead to a kind of decision ethics that does not reflect carefully enough the challenges and demands that the acting subjects are really confronted with in this specific situation and within the specific relationships of the situation. However, if those are not reflected enough, such a decision ethics becomes unethical, as it becomes unaware and thoughtless. I told the seminar participants that 
I would rather consider it as unethical to support one of the two options with arguments. I pointed out that it was necessary to take a much closer look at the situation itself. If I was to contribute to the solution, I would have to visit the department and experience the situation. Why is the lady refusing to wash herself? What is she afraid of? What is the influence of the department on her behaviour? Who from the staff might have a good relationship with her - a relationship that might enable it to make her take a shower or wash herself without turning it all into a general dilemma of forced treatment? Maybe some staff members should simply stay away from the lady in this situation (as the persuasion faction indicated)? If the lady should really be helped, the situation would have to be broadened, and the interpersonal relationships would have to be looked at more carefully. Making a classroom decision would only please the interests of the staff. For the lady, it could even be harmful. And if so, would then the so-called solution really be helpful for the staff?

I have warned of an ethics that strives for decisions. In this paper, I prefer to hint at another ethical way of thinking that I call "relation ethics". What do I mean when I say "relation ethics"? First I would like to explain how I use the terms "morals" and "ethics". In everyday language, we use the terms "morals" and "ethics" as synonyms. However, it might be useful to give them a slightly different meaning: When I talk about morals, I am referring to the norms, customs and traditions we are guided by in our actions. We live by morals, while by contrast, ethics is moral theory. This moral theory may be descriptive or normative. If it is descriptive, it falls into science; it covers the morals actually prevailing within a group or a society. A more ambitious project is to develop a normative ethics, which will then be an attempt to determine and justify what are good and valid morals. While descriptive ethics will only describe the morals that actually prevail, normative ethics aims at determining which morals should also prevail. The latter type of ethics is not science and falls into moral philosophy.

We can subdivide normative ethics into action ethics and relation ethics (cf. Lindseth, 1992). According to action ethics, to reason means to explain the choice of an action in situations in which the active subjects (as well as other persons) are not sure what 
is the right thing to do. It answers the question: What should I do? On the other hand, reasoning due to relation ethics implies a reflection on how to meet the challenge inherent in the situations and relationships we enter. Relation ethics cannot simply replace action ethics, because quite often we have to justify our actions. Nonetheless, the danger is that we take relation ethics too easily, and that we want to reach a quick solution. Relation ethics is of crucial importance because it shows what is at stake when making decisions that affect other people. Relation ethic makes visible how vulnerable we are when trusting or having to trust other people. I would like to point out the importance of this ethics by going into the relation ethics of the Danish philosopher Knud E. Løgstrup mentioned above.

\section{Trust - and the spontaneous and sovereign expressions of existence}

In the first chapter of his book, The Ethical Demand, Løgstrup (1956/1997: 8) starts with the words: "It is a characteristic of human life that we normally encounter one another with natural trust." Many people might put the book away after reading this sentence. It is naive to think, one might object, that people are so trusting. Just look at what the world is like: Mistrust and suspicion often rule - but not trust. Even so, Løgstrup does not say that people are usually trusting. He does not comment on certain characteristics of people or on basic trust, but rather on a kind of "trust which, on a basic understanding, belongs to human existence". We are only able to become trusting persons and develop basic trust, a trusting attitude, to such an extent as the elementary trust has not been disappointed in our first life stage. But trust as an attitude and trust as an elementary expression of existence are not exactly the same. Simplified a little, we might say that an attitude is "within us" and tied to the character, whereas the expression of existence is "between us" as something that belongs to human existence. This expression of existence is a moral power that we can choose to give space to or to exclude.

We experience it as something natural if a human being meets another human being with trust. Normally, we are not surprised, as it would be odd to ask: "Why are you so trusting?" However, if this person is full of mistrust and suspicion, it would not be odd to ask: "Why are you so mistrusting? What happened that you are so full of suspicion?" From this, it becomes clear that we have to give reasons for mistrust, but 
not for trust. We usually do not need a reason to trust, whereas mistrust has to have a reason. In this sense, trust belongs to our life. We can have a lot of reasons to mistrust, so that we are often everything but trusting. But how would we live if we needed reasons for trust, but not for mistrust? We could not stand that. It would not be life. Trust is an expression of life. It belongs to life. It is a principal moral phenomenon that does not need any justification.

After publishing, "The Ethical Demand" in 1956, Løgstrup developed his term "expression of existence" in his book on Kierkegaard in 1968. Not only trust but also hope, openness in speech, compassion and charity are all expressions of existence.

Trust is the expectation to be recognized, accepted and respected. If we dare to enter the world with our wishes, our engagement and our will, we expect to be welcomed. I am not talking about naive trustfulness or unlimited openness, but rather about an expectation that is self-evident and natural in a sense that it does not need justification. It belongs to existence. The same can be said about the other expressions of existence. Hope is the self-evident and natural expectation that things will turn out well if we dare to enter the world with our wishes, our engagement and our will, an expectation that also does not need any justification. I am not talking about the belief in a happy future. Hope as an expression of existence does not exclude the recognition of problems, conflicts and suffering to come. Openness of speech is a basic element of speaking, of which we might not be aware. Our speech is open in the sense that we do not need a reason to say what we think, whereas we need a reason not to. Still, we quite often have a number of reasons to hold back our speech, so that we do not experience it as open, but rather as zig-zagging. Compassion, our direct understanding of somebody else's situation, also does not need reasons, and neither does charity, our direct "impulse to free another person from his or her suffering" (Løgstrup, 1982: 107).

The expressions of existence are working best if we do not think about them. They open us up for someone else whom we trust or with whom we are charitable. If we start thinking: "Now, I am charitable or trusting", then an element of mistrust or calculation has already emerged. The expressions of existence are spontaneous and 
unfold silently, and they are also sovereign. We do not have the power to take away their position as basic ethical phenomena. We must not necessarily give them room in our life. We can live with suspicion, desperation, hate and cruelty, but we cannot cancel trust, hope and charity from our lives. Especially in humiliation and injustice, in crisis and in conflicts, the expressions of existence announce themselves as absent: We experience that they are missing! When the expressions of existence are ruling, we do not have to think about them, but when they are missing, we have to think about them. Crises and conflicts, Løgstrup says, bring back to our consciousness the expressions of existence.

When trust is disappointed, and when compassion and charity stay away, then mistrust and suspicion, hopelessness and self-contempt, in addition to contempt and indifference, coldness, hate and cruelty, all enter our life. These forces are also spontaneous, but they do not unfold silently. We experience them as "thought feelings that go their forced and circling ways", Løgstrup (1982: 105) writes. They have contents that we are forced to think about: Why did he react in such a way? Why have I not said anything? I should not have done that! What a hopeless case do they take me for? We should not have accepted that! Away with that rabble! These thoughts are emotionally loaded. They deal with something which does not let go, which is insistent and which keeps circling around the same questions, the same doubts, the same fears, the same hate. Circling thought feelings calm down after some time, they stop grinding. But a certain tension remains. Situations and events can easily touch sensitive topics and send these thoughts back to their upset circles.

\section{The ethical demand and social conventions}

By talking about spontaneous and sovereign expressions of existence, Løgstrup demonstrates how co-dependent we are as human beings. In trust, in openness of speech and in charity, we are moving towards the Other. However, the Other, now has the power to take care of that what we want to give him or to refuse it. In trust, we put something from ourselves into his hand, and he can accept it or let it drop. In trust, we are vulnerable. "A person”, Løgstrup (1956/1997: 15f) writes, "never has something to do with another person without also having some degree of control over him or her. It may be a very small matter, involving only a passing mood, a 
dampening or quickening of spirit, a deepening or removal of some dislike. But it may also be a matter of tremendous scope, such as can determine if the life of the other flourishes or not." We like to think that we are independent of each other, and hopefully we are - in the sense that we can live independently, but nevertheless our lives are deeply tangled up with each other. Out of this basic fact that we always have something of the Other's life in our hand, the ethical demand directly arises: to take care of that of the Other what he has laid into our hand (cf. 1956/1997: 16f).

It has dramatic consequences that in relationships we always have the Other's life in our hand. In the last consequence, we have the power to maintain or destroy each other. We can hold or let each other drop. However, we do not experience these extremes as actual alternatives. If we claim that life is about maintaining or destroying the Other, most people would protest, at least if they had not heard about trust as a expression of existence. They would brush aside this claim as exaggeration. Yet it has a reason, Løgstrup emphasizes, that we do not experience the extremes. It is true that we can maintain or destroy each other, we are just spared most of the time to realize this power. What spares us are the forms of social life, the social conventions, the customs and traditions, the roles and institutions. According to Løgstrup (cf. 1956/1997: 19f), these forms of social life have a double function. First, they save us from psychic exposition. We want to achieve something, we want to do something, and if we stick to the conventional forms and social customs, we do not have to be afraid too much of being exposed, of putting something into the Other's hand that is not taken care of. Thus, we can more or less predict how we are going to be accepted. For example, imagine that you want to buy bread and milk. This is not unimportant, because you need bread and milk so that your children are not hungry. Yet, this is not a problem when you enter a shop, because hopefully you will be recognized as a customer by the vendor. Hence, you do not have to be afraid that he or she looks at you and says: "So you think you can buy bread and milk here?" Or, when walking through the forest, we can be rather sure that the stranger we are greeting is greeting us back. We do not really have to be afraid that he/she will come up to us with a club and strike us down - which might at least be possible. Conventional forms of social life prevent our lives from becoming a risky enterprise. 
"Conventions" and "conventional" are terms that might easily have a negative connotation. Social conventions may save us from psychic exposition, but maybe sometimes too much so. We become conventional in the sense that we become stiff and do not show ourselves anymore. For instance, we might be polite, but at the same time cold and reserved. For this reason, one might think it would be better to give up conventions and to just live and act naturally. However, this would be a fallacy, as Løgstrup points out when explaining the second function of social conventions. They not only protect us from the unpleasant, they also make possible a successful human self-expression. Without social conventions, we would not know how to put into practice our wishes and decisions. Acting would not only be a risk, our way of expressing ourself would also become clumsy and rude, maybe even brutal and destructive. A rich repertoire of social conventions gives the active subject a register to play upon. It is therefore characteristic for a rich culture to have conventional forms that help people to organize things and communicate with each other. A good life would therefore not be possible without the conventional forms of the culture.

\section{The love relationship}

But regardless of how good we know and master these forms, we still cannot always avoid that we reach the boundaries of what these forms are capable of. Life then becomes more critical, and we then start to experience that we in fact are able to maintain or destroy each other. Løgstrup demonstrates this by using an example that we (hopefully) all know: a love relationship. In such a relationship, we quickly reach the boundaries of social conventions. Being accepted or not in a love relationship is not a matter of social conventions, but rather of the other's goodwill. At the same time, it is also important for us that we are accepted by the other person, because this person is not just an ordinary person that holds something from our life in his or her hands but rather an almost mythical being of whom we expect to satisfy our deepest needs and desires. Just imagine that we dare to come out of our shell, e.g. with a wish or with a suggestion, and the other person has no sense for our concern, or she or he does not even recognize it - which might not be surprising if we expressed it in an indirect or encoded way. Nonetheless, we now experience this as exposition. We have put something from ourselves, even something important, into 
the other's hand, and he or she has rejected it. We experience a psychic exposition that hurts. In the language of psychodynamic psychology, one could talk about a narcissistic offence. If we were able to admit or tell the other that we experience it as painful that he or she had rejected our concern, the other might be struck and affirm that he or she did not mean to reject us - maybe we could express our concern once more. The problem, however, is that it is very difficult for us to admit these psychic exposures - even in front of ourselves. It is just too painful, and it too much puts into question our existence. But if we do not open up for the experience of pain, we are necessarily taken away by the movement of pain - we have no other choice. This movement can take two directions. It can turn inwardly, as self-accusation. But quite often it turns outwardly and takes the form of accusations or reproaches. "You cannot do that with me! I will not accept that. And moreover, you did not only do this right now, you also reacted like this several times last week. If this is not going to stop ..." - and then we have threats of withdrawal and of parting.

In an intimate relationship, we hence enter a dramatic field. We cannot protect ourselves from psychic expositions. We are much more naked than in other relationships, and not only physically. We quickly move from the happy state of being carried to the desperate state of being dropped. If the relationship shall not break apart, it has to find or develop ways that it can rest upon - if possible, forms that keep it from turning into a Strindberghian drama.

The pain of psychic exposition expresses itself in the form of moralizing. "This cannot be! This is impossible! That cannot be tolerated!" Moralizing does not want communication, it condemns. It does not include, but rather excludes. Løgstrup calls this, "the immorality of the moral". Not the other person him/herself, but rather a distorted image of him/her rises in our consciousness. Not love, but only justice is at stake: "I want my right, even if it takes eight trials!" Or even worse: "I want my right, even if it costs me my life!" Then the state of war has begun.

Life, Løgstrup emphasizes, is a movement towards the Other. In this movement, we are extremely vulnerable. We easily feel not accepted, but instead ignored. 
Sometimes, we are really heavily offended or hurt. The sovereign expressions of existence have to leave, and the circling thought feelings take control.

\section{The ethical demand is unspoken: How to respond to it?}

The ethical demand is that we shall take care of that which the Other puts into our hands. However, this demand is not identical with what the Other explicitly demands. The ethical demand is not spoken out, and it is not so easy just to ask the Other: What is it you demand from me? The Other's ethical demand addressed to us is something we have to recognize ourselves. We have to see it, and to know ourselves how to deal with it. How do we do that?

There is no general rule how to respond to the Other's ethical demand. There is no recipe as to how to behave because you probably will have to behave differently from case to case. Even so, something can be said about how not to respond to the ethical demand. You could confront the Other paternalistically in a know-it-all manner, not really ready to listen because you already know it all. You could also confront the Other with an attitude you might call flattering, an attitude in which you always agree because you do not want to be contradictory. These two attitudes, the know-it-all one and the flattering one, seem to be opposites at first glance, but they have something essential in common: They simplify the task of the encounter and they avoid any confrontation, either by eliminating the Other's opinion or by eliminating mine.

First, in order to respond to the ethical demand, a person whose expression we recognize has to be acknowledged, and second, we have to dare an encounter, which also means to contradict the Other if necessary. We have to listen to the Other and take him seriously, but we must not give up our own authority. How we exactly do this very much depends on the relationship we have to the Other. The ethical demand that somebody addresses to us is not the same if we are his or her teacher, doctor, friend, colleague, priest, therapist, counsellor or the social worker in charge. The social position we have towards the Other is our chance for a helpful encounter. 
Therefore, we have to clarify ever anew how to respond to the ethical demand. If we want to understand what really counts when holding a part of the Other's life in our hands, we have to take a closer look at the individual cases, and describe and analyse them. Let us turn to a brief case description.

Once, the social psychiatrist and family therapist from Troms $\emptyset$, Tom Andersen (19362007), told me that a therapist had asked him to talk to a manic patient at a Troms $\varnothing$ psychiatric hospital. The patient, a man in his $40 \mathrm{~s}$, is talking so incessantly and loudly that it is hardly possible to get into a dialogue with him. Tom Andersen recognizes that in the patient's Norwegian flood of words, the English word "space" is mentioned frequently. After a while, Tom says: "I heard you using the word 'space.' This is a word I usually don't use in my Norwegian language. Can you explain to me what you mean by it?" For the first time, the patient takes a brief and thoughtful pause. He then says that he relates the term "space" to a space of negotiation, to the possibility of exchange, a possibility that Tom Andersen represents for him. After clarifying this - which at the same time means understanding the encounter - a dialogue starts that is very upsetting, but which is still quite understandable.

I think this short case description may illustrate what it means to meet the ethical demand of the Other. By using the word "space", the patient expresses something that is important to him. It might not be clear what is meant by the word, but Tom Andersen still feels that something is put into his hand, something that has to be taken care of. Tom does not know why the term "space" is important, but he wants to find out. The ethical aspect of this enterprise is that it helps the patient to open up and be approached. The epistemological or hermeneutic aspect of this enterprise is that he wants to understand the patient's utterance. In this attempt of an approach to understanding, he is following a basic hermeneutic principle. He gives attention to that which touches him, although he does not understand it. He is following the principle of letting oneself be guided by a touched not-knowing. I call this the "principle of touched not-knowing" (Lindseth, 2001: 134). This principle implies a willingness not to know, an openness to the fact that the Other might say something that we do not understand, but that we want to understand, because we feel it concerns us, we feel it might be important or even crucial. This principle is a basic 
principle of hermeneutics, because the reading of a text normally presupposes an expectation that this text could tell us something new or interesting. I think this sounds quite obvious. However, we should not think that this principle of touched notknowing is applied self-evidently in health services or in social work. As a general rule, we want to know rather than not know - we want to understand, to grasp, to know what is the matter, to get an answer. This is why we use our knowledge all too quickly. The question in its openness is hardly on the table - and we already think we have an answer. For instance, we might ask ourselves what the word "space" could mean - but we already know: It is just a delusion. In this case, we push away the patient. We do not take care of that which he has put into our hands.

From this short case description, we can now understand a little better what it means to meet the ethical demand of the Other. It means to follow a basic hermeneutic principle, namely the principle of touched not-knowing. This principle also expresses a fundamental attitude towards other human beings: What the Other expresses is important and deserves to be taken seriously. The expression of the Other deserves to be heard and seen. From the standpoint of relational ethics, it is of crucial importance to have the willingness to open up to the meaning of what the Other expresses, even if -especially if! - the meaning is not clear to us.

It is easy to give an example of an unclear and hidden expression of the Other: We can imagine the Other as being silent. It is not clear what this silence means, because it is not spoken out, but simply just expressed as silence. To act ethically in this case means to open up for the expression of silence. How do you do that? You let yourself be touched and moved by the expression of silence, and you start following this movement - with your own gestures, with your breath, with the direction of your gaze. It is not difficult to do this if we only understand that it is important, and the expression of silence can catch our full attention if you open up for it. Usually, however, we do not open up for such expressions. We all too easily leave the principle of touched not-knowing because our education tells us: This expression is out of place. The Other shall not be silent, but rather talk. And if he talks, we quickly think that he should not say what he is saying, but rather say what we want to hear. In this way, we do not take care of the Other's fragile expression, but instead judge that it 
was out of place or unsuccessful. This judgement is a refusal of the Other, which is fatal for the following reason: It is usually tied to the Other's self-understanding; the Other already knows that he cannot cope with his situation. Here, we enter a vicious circle: A failing expression of life is reinforced and thereby supported.

In this paper, I have shown how the common ethical way of thinking tends to primarily justify the decisions of the active subject, and how it can become thoughtless. It easily overlooks the Other's self-expression, which is vulnerable and at our mercy. From our own experience, especially in love, we know how much we are at each other's mercy, but this knowledge of the vulnerability of individual expression quite often does not lead to consequences when working professionally with patients or clients.

\section{Overlooking the ethical demand of the Other - in social work (and in all kinds of helping activities)}

It is not easy for us to take care of what the Other puts into our hands from his or her life. Again and again, we leave the principle of touched not-knowing. Why is that so? We might say that we do not respect other human beings enough, and that we do not recognize human dignity enough. But social workers and all who want to act ethically would contradict this explanation. Now, at the end of my paper, I would therefore like to give another answer. I think social workers (and all types of professional helpers) are educated to a way of thinking that systematically overlooks the vulnerable human self-expression. In understanding human behaviour or life, professional helpers are educated not so much to see it as expression, but rather as something that either has a cause or an aim. We are either looking for causes and reasons or for aims and goals that shall make it understandable for us. As helpers, we tend to look back or forth, so to speak, without realizing the expression in between, here and now. We are looking for explanations, and especially if we do not understand a certain behaviour or life, we ask for such explanations. We suppose that this person has made certain experiences that influenced his or her behaviour, or maybe he or she has put up problematic goals or does not know what kinds of means to use in order to achieve them. 
I think that the direction of our gaze, this looking either back or forth, is a reason for overlooking the vulnerable self-expression and nakedness of human life. And this ignorance is understandable because social workers (as with other professional helpers) have learned a lot through years of education about the needs of the clients due to limiting experiences in childhood and later, as well as due to deficits in realizing goals in life. Theories about past harm and future learning become a priority in the minds of educated helpers who wish to act professionally.

It would not be surprising if you, my reader, were now to raise two questions. First, you might ask if I am saying that we should not look at the causes and aims of human life anymore, but only at the life expressions. No, I am not saying that. We need all three perspectives - but particularly the last one, the perspective on expressions!

Second, I would expect a question if the causes and aims might not still be more important than the expression when dealing with suffering human beings in psychiatry, in health care or in social work. No, I want to say with emphasis, especially for those who are poor and weak, it is so important to mind their actions and their lives as expressions (cf. Lindseth, 2012). These expressions are full of crucial and important experiences. Even if they might seem odd, they deserve to be recognized and taken seriously.

Munich, Germany, June 10, 2014 


\section{References}

Lindseth, A. (1992). The Role of Caring in Nursing Ethics. Tidsskrift for norsk sykepleieforskning, no. 1, 51-59.

Lindseth, A. (2001). What The Other Says - And What (S)He Talks About: Some Foundations of a Theory of Philosophical Practice. (Lecture at the 5th international conference on Philosophical Practice, Oxford, July 27-29, 1999.) In: T. Curnow (Ed.), Thinking Through Dialogue. Essays on Philosophy in Practice, 134-136. Surrey: Practical Philosophy Press.

Lindseth, A. (2012). Being III as an Inevitable Life Topic - Possibilities of Philosophical Practice in Health Care and Psychotherapy, Philosophical Practice, 7, 1081-96.

Løgstrup, K. E. (1968). Opgør med Kierkegaard. København: Gyldendal.

Løgstrup, K. E. (1972). Norm og spontaneitet. Etik og politik mellem teknokrati og dilettantokrati. København: Gyldendal.

Løgstrup, K. E. (1982). System og symbol. Essays. København: Gyldendal. Løgstrup, K. E. (1997). The Ethical Demand. Notre Dame/London: University of Notre Dame Press. (Danish original, Den etiske fordring, first published 1956.) 